20

\title{
Спектральный мониторинг процесса иммобилизации препарата нафтифин в субмикронные частицы ватерита*
}

\author{
() О.И. Гуслякова, Е.В. Ленгерт, В.С. Аткин, В.В. Тучин, Ю.И. Свенская
}

Саратовский национальный исследовательский

государственный университет им. Н.Г. Чернышевского,

410012 Саратов, Россия

e-mail: olga.gusliakova17@gmail.com, svenskaya@info.sgu.ru

Поступила в редакцию 18.11.2018 г.

В окончательной редакции 11.01.2019 г.

Принята к публикации 31.01.2019 г.

\begin{abstract}
Одним из наиболее интенсивно развивающихся направлений научных исследований является создание систем доставки лекарственных средств, позволяющих одновременно повысить дозу терапевтического агента в зоне патологии и снизить токсический эффект для организма в целом. В рамках данной концепции нами проведено исследование, связанное с разработкой методики иммобилизации противогрибкового препарата „Нафтифин““ в субмикронные контейнеры на основе частиц ватерита. С этой целью рассмотрены два подхода к включению антимикотика: путем его адсорбции из раствора на поверхность готовых контейнеров и соосаждения в процессе синтеза ватеритных частиц. Различные оптические методы были применены с целью мониторинга процесса иммобилизации препарата. Успешность иммобилизации противогрибкового препарата подтверждена спектрами комбинационного рассеяния. Количественная оценка эффективности загрузки нафтифина в ватеритную матрицу проведена спектрофлуориметрическим методом. В результате установлено, что наибольшее содержание антимикотика в частицах ватерита (9\% wt) достигается в процессе его соосаждения. Методом сканирующей электронной микроскопии было проведено исследование стабильности частиц с иммобилизованным препаратом в деионизованной воде, физиологическом растворе и культуральной среде. Было продемонстрировано замедление процесса перекристаллизации ватеритных носителей в среде, содержащей белки. Такой эффект дает основание ожидать пролонгированное высвобождение лекарственного препарата из частиц ватерита в живом организме.
\end{abstract}

DOI: $10.21883 /$ OS.2019.05.47662.11-19

\section{Введение}

Нерациональное использование противомикробных препаратов, включающее их чрезмерное применение, полипрагмазию, а также назначение инъекций в случаях, когда для лечения подходят пероральные или наружные формы препаратов, приводит к развитию резистентности микроорганизмов, что сопровождается ростом уровня заболеваемости, а также постоянным повышением расходов на нужды здравоохранения. Разработка подходов, обеспечивающих эффективное применение существующих противомикробных препаратов, является актуальной задачей. Повышение терапевтической эффективности противогрибковых средств возможно благодаря увеличению их локальной концентрации, а следовательно, вероятности аккумуляции в области поражения, что обеспечит уменьшение дозы используемого препарата одновременно со снижением токсических эффектов, связанных с его приемом.

\footnotetext{
* The 22nd Annual Conference Saratov Fall Meeting 2018 (SFM'18): VI International Symposium „Optics and Biophotonics“ and XXII International School for Junior Scientists and Students on Optics, Laser Physics \& Biophotonics, September 24-29, 2018, Saratov, Russia. https://www.sgu.ru/structure/fiz/saratov-fall-meeting/previousconferences/sara
}

В последние десятилетия особенной популярностью пользуется разработка подходов, связанных с иммобилизацией антимикотических средств в различные наноразмерные и субмикронные контейнеры [1]. С этой точки зрения интересным является применение частиц ватерита в качестве матриц-носителей антимикотика. Частицы ватерита принадлежат к полиморфной модификации карбоната кальция [2]. Простота получения таких частиц, возможность управления их размером в пределах от $300 \mathrm{~nm}$ до $6 \mu \mathrm{m}$, высокая эффективность загрузки различными биологически активными веществами, биосовместимость [3-5], а также мягкие условия растворения $(\mathrm{pH}<5.5)[6,7]$ делают их привлекательными в качестве систем доставки лекарственных средств как для лечения местных заболеваний, так и для проникновения лекарств в системный кровоток. В последние десятилетия активно обсуждается потенциал частиц ватерита в области доставки лекарственных средств с контролируемыми условиями высвобождения загруженных активных веществ $[3,8,9]$.

Частицы ватерита обладают сферической или эллиптической формой, диаметр их пор составляет $30-50 \mathrm{~nm}$ [10]. Пористость частиц ватерита обеспечивает возможность их эффективной загрузки биологически активными веществами благодаря тому, что иммобилизация осуществляется не только на 
поверхность частиц, но и в объем [10]. Ранее была показана возможность иммобилизации широкого спектра биологически активных веществ, таких как белки [11-13], ферменты [14,15], РНК [16], различные лекарственные препараты $[6,17]$ и др.

Будучи наименее стабильной фазой карбоната кальция, ватерит медленно растворяется и перекристаллизуется в кальцит при контакте с водными растворами. В зависимости от иммерсионной среды частицы ватерита либо полностью растворяются, либо переходят в кальцит в результате ионизации внешнего слоя их поверхности. Высвобождение иммобилизованного вещества из ватеритной матрицы-носителя сопровождает процесс ее растворения и перекристаллизации, причем полное высвобождение происходит, когда частицы ватерита полностью переходят в кальцитную фазу. Контролируя фазу частиц, можно судить о скорости высвобождения иммобилизованного вещества [18-20]. Благодаря описанным выше свойствам частицы ватерита рассматриваются как перспективный носитель лекарственных средств $[8,16]$.

В настоящей работе была исследована возможность иммобилизации противогрибкового препарата „Нафтифин“ в субмикронные контейнеры на основе частиц ватерита. Данный препарат относится к классу производных аллиламина, эффективен против большого набора патогенных грибов, показал успешную терапию нескольких типов дерматомикозов при наружном применении [21,22]. Мониторинг процесса иммобилизации антимикотика осуществлялся при помощи таких спектральных методов, как флуориметрия и комбинационное рассеяние света. Кроме того, с помощью метода сканирующей электронной микроскопии была исследована кинетика изменения кристаллической модификации полученных контейнеров в различных средах in vitro c целью оценки длительности высвобождения иммобилизованного препарата.

\section{Материалы и методы}

\section{Материалы}

Для синтеза частиц ватерита были использованы хлорид кальция $\left(\mathrm{CaCl}_{2}\right)$ и карбонат натрия $\left(\mathrm{Na}_{2} \mathrm{CO}_{3}\right)$, этанол (Ethanol), полученные от Sigma-Aldrich (США), а также этиленгликоль, полученный от АО „Экос-1“(Россия). Антимикотический препарат „Нафтифина гидрохлорид“ (нафтифин) был полученен от Sigma-Aldrich (США). Все химические реактивы были использованы без дальнейшей очистки. На всех стадиях эксперимента была использована деионизованная вода, полученная с помощью системы очистки воды Milli-Q (США).

\section{Синтез частиц ватерита}

За основу при синтезе частиц была взята методика, описанная в работе [20]. Таким образом, для приготов- ления чистых частиц ватерита 0.33 М-водные растворы солей $\mathrm{CaCl}_{2}$ и $\mathrm{Na}_{2} \mathrm{CO}_{3}$ объемами по $2 \mathrm{~mL}$ каждый были смешаны с $10 \mathrm{~mL}$ этиленгликоля. Затем осуществлялось перемешивание полученной реакционной смеси с помощью магнитной мешалки при скорости $700 \mathrm{rpm}$ в течение $3 \mathrm{~h}$. Образовавшиеся частицы были осаждены путем центрифугирования при скорости $6000 \mathrm{rpm}$, а затем трижды промыты водой и однократно этанолом. Готовые частицы были высушены при температуре $60^{\circ} \mathrm{C}$ в течение $1 \mathrm{~h}$.

\section{Иммобилизация лекарственного препарата „Нафтифин“ в частицы ватерита}

Иммобилизация антимикотика была проведена двумя способами: путем его соосаждения с частицами ватерита в процессе их синтеза, а также путем его адсорбции из раствора на поверхность готовых частиц. Навески препарата, взятые для иммобилизации каждым из двух методов, были идентичными друг другу и выбраны с точки зрения соотношения массы препарата к массе носителей (1 mg нафтифина гидрохлорида на $10 \mathrm{mg}$ частиц карбоната кальция). Для соосаждения антимикотика с частицами ватерита к смеси этиленгликоля и водного раствора соли $\mathrm{Na}_{2} \mathrm{CO}_{3}$ был добавлен нафтифин гидрохлорид массой $5 \mathrm{mg}$. Выход частиц по массе в этом случае составил $52 \pm 3 \mathrm{mg}$. Для адсорбции препарата к уже готовым частицам ватерита $(10 \mathrm{mg})$ был добавлен спиртовой раствор нафтифина гидрохлорида в объеме $1 \mathrm{~mL}$ с концентрацией $1 \mathrm{mg} / \mathrm{mL}$.

\section{Спектральные методы исследования процесса иммобилизации препарата}

Для подтверждения включения молекул лекарственного препарата „Нафтифин“ в структуру субмикронных частиц ватерита были изучены спектры комбинационного рассеяния полученных образцов. Измерения спектров были проведены с помощью спектрометра Renishaw InVia (Renishaw) с объективом 50X/0.5 n.a. на длине волны лазера $532 \mathrm{~nm}$ мощностью $0.15 \mathrm{~mW}$ и CCDдетектором в диапазоне колебательных частот от 800 до $2000 \mathrm{~cm}^{-1}$. Спектры были записаны для носителей, полученных методом соосаждения. Статистика набиралась минимум по 5 частицам из разных участков образца, измерение проводилось в трех точках для каждой частицы.

Количественная оценка эффективности загрузки контейнеров была проведена путем измерения спектров флуоресценции в диапазоне 312-500 nm при возбуждении излучением на длине волны $285 \mathrm{~nm}$ при помощи прибора (Synergy H1, BioTek). Для построения калибровочной прямой были получены спектры флуоресценции различных концентраций препарата „Нафтифин“, приготовленные в этаноле (рис. 1,a) и этиленгликоле (рис. 1,c), чтобы иметь возможность оценить количество инкапсулированного препарата. Максимум 

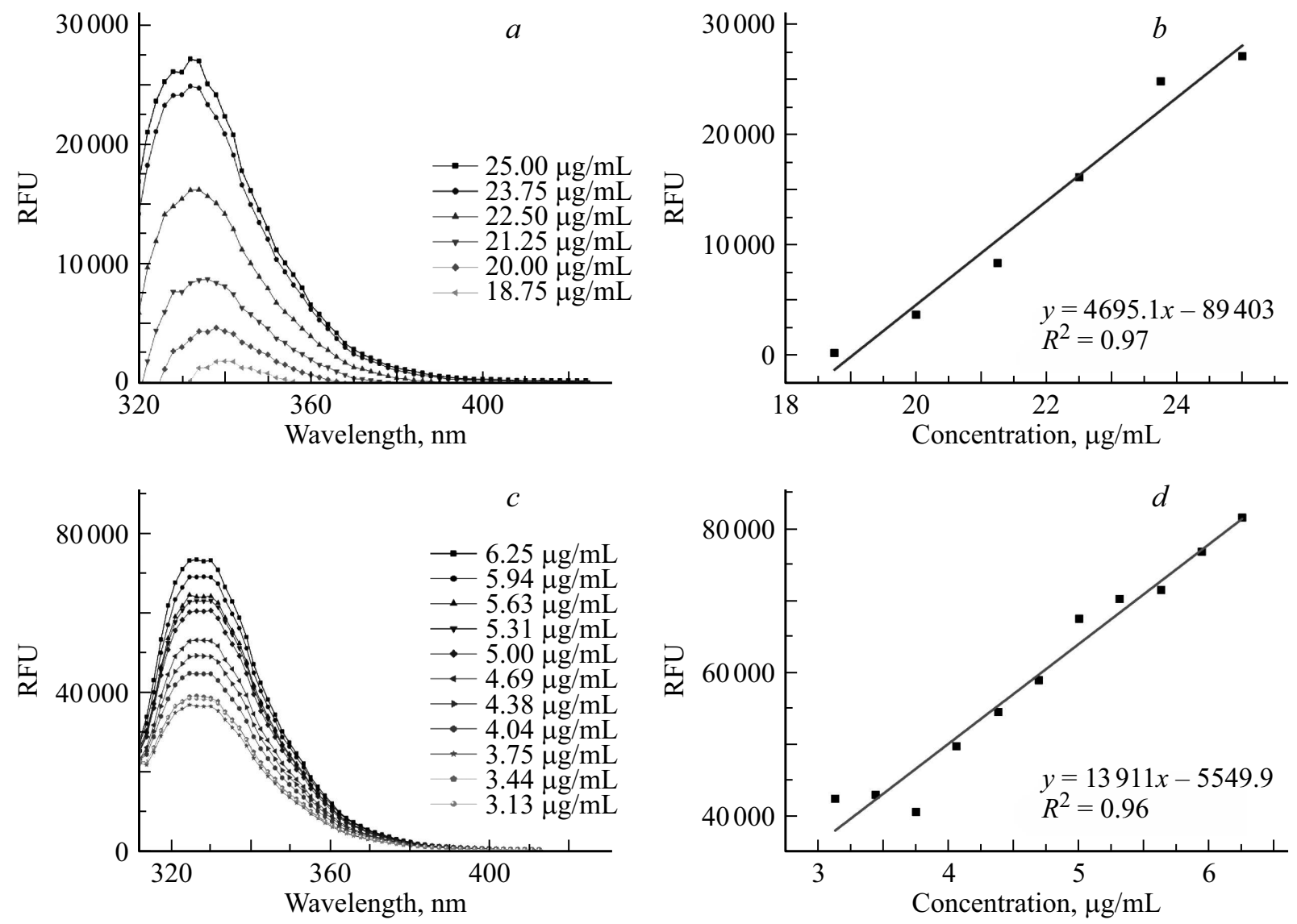

Рис. 1. Калибровка растворов нафтифина в этиловом спирте и этиленгликоле: $(a)$ спектры растворов нафтифина с различной концентрацией в этаноле; $(b)$ калибровочная кривая, полученная для зависимости относительных флуоресцентных единиц от концентрации нафтифина в спирте; (c) спектры растворов нафтифина с различной концентрацией в этиленгликоле; (d) калибровочная кривая, полученная для зависимости относительных флуоресцентных единиц от концентрации нафтифина в растворе этиленгликоля.
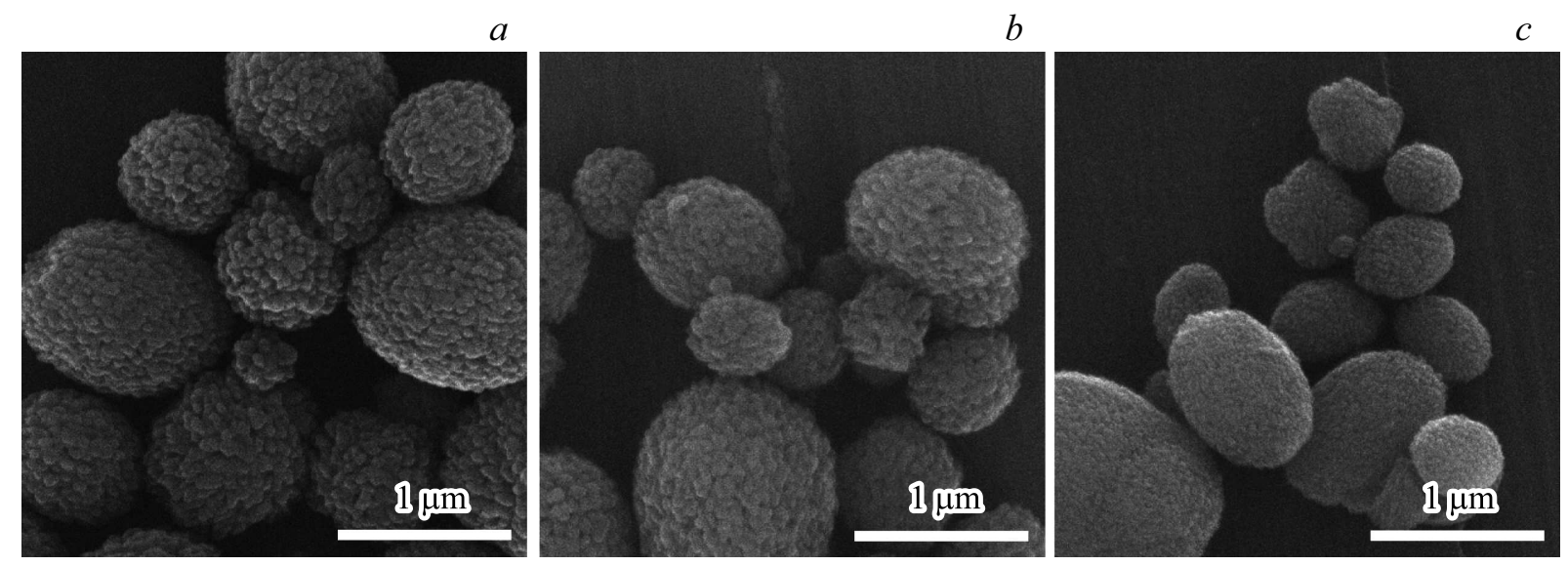

Рис. 2. СЭМ-изображения: (a) ненагруженных частиц ватерита; $(b)$ частиц ватерита, нагруженных антимикотиком методом его адсорбции; $(c)$ частицы ватерита, нагруженных антимикотиком методом соосаждения.

флуоресценции в обоих случаях находился на длине волны $332 \mathrm{~nm}$.

Для оценки эффективности загрузки частиц ватерита нафтифином были измерены супернатанты (надосадоч- ные жидкости), отобранные после проведения адсорбции и соосаждения антимикотика. Полученные значения флуоресценции для каждого супернатанта были соотнесены с калибровочными кривыми (рис. $1, b, d)$, что позво- 

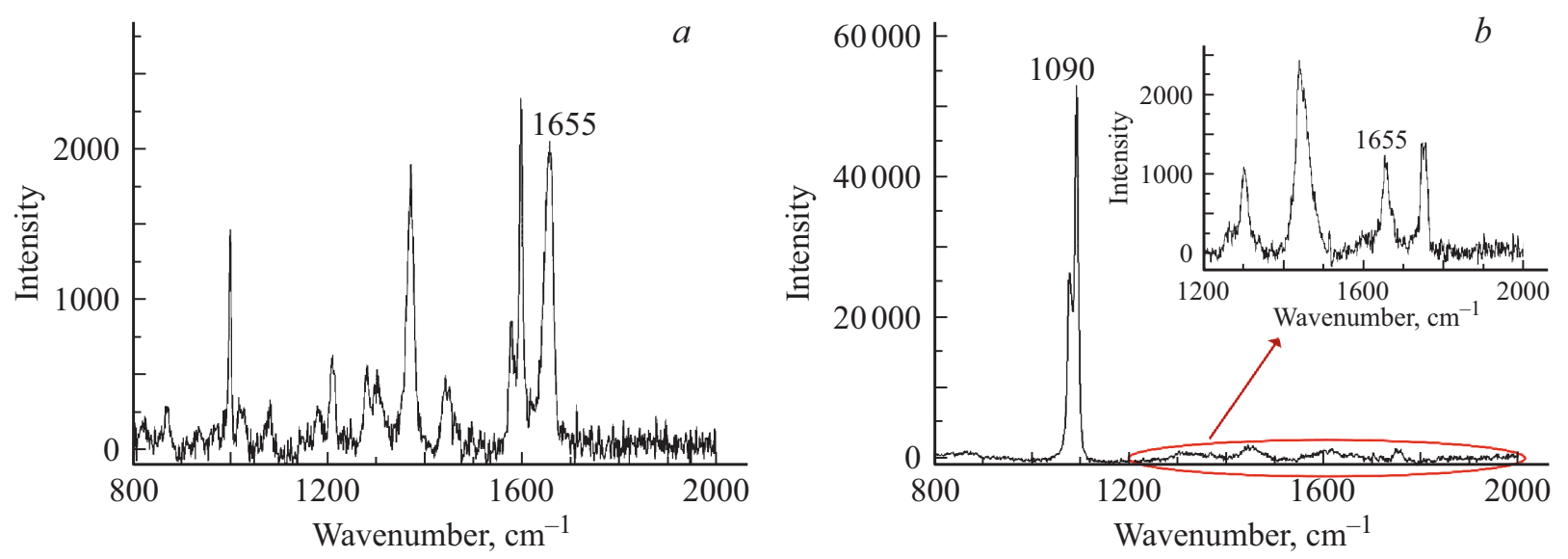

Рис. 3. Спектры комбинационного рассеяния, полученные при исследовании (a) свободного лекарственного препарата „Нафтифин“, $(b)$ частиц ватерита, содержащих препарат „Нафтифин“.

лило рассчитать концентрацию препарата, оставшегося в растворе. Для расчета массы препарата, иммобилизованного в ватеритную матрицу, была использована следующая формула:

$$
m_{\mathrm{NF}^{\prime}}=c_{\mathrm{NF}^{0}} V_{\mathrm{NF}^{0}}-c_{\mathrm{NF}^{*}} V_{\mathrm{NF}^{*}},
$$

где $m_{\mathrm{NF}^{\prime}}$ - масса нафтифина, иммобилизованного в ватеритную матрицу, $c_{\mathrm{NF}^{0}}-$ концентрация исходного раствора нафтифина, $V_{\mathrm{NF}^{0}}-$ объем исходного раствора нафтифина, $c_{\mathrm{NF}^{*}}$ - концентрация нафтифина в отобранном супернатанте, $V_{\mathrm{NF}^{*}}$ - объем отобранного супернатанта.

\section{Исследование стабильности ватеритных контейнеров в различных средах}

Было проведено исследование кинетики перекристаллизации частиц ватерита, содержащих антимикотик, при инкубации в различных средах: деионизованная вода, физиологический раствор $(0.9 \% \mathrm{NaCl})$ и среда для культивирования клеток (Minimum Essential Medium с добавлением $10 \%$ инактивированной эмбриональной бычьей сыворотки FBS и $1 \%$ смеси антибиотиков стрептомицина и пенициллина). Для этого навески частиц массой $5 \mathrm{mg}$ были инкубированны в указанных средах в объеме $1 \mathrm{~mL}$ при постоянном встряхивании $700 \mathrm{rpm}$ и температуре $37^{\circ} \mathrm{C}$. На временнб́х промежутках в 1 , $2,3,5,7,9$ и 10 дней были отобраны капли объемом $1 \mu \mathrm{L}$ из каждого образца и нанесены на кремниевую подложку для изучения морфологической структуры частиц ватерита с помощью сканирующего электронного микроскопа (CЭM) MIRA II LMU (Tescan) при рабочем напряжении $30 \mathrm{kV}$.

\section{Результаты и обсуждение}

Исследование морфологии частиц ватерита как чистых, так и нагруженных антимикотиком было прове-

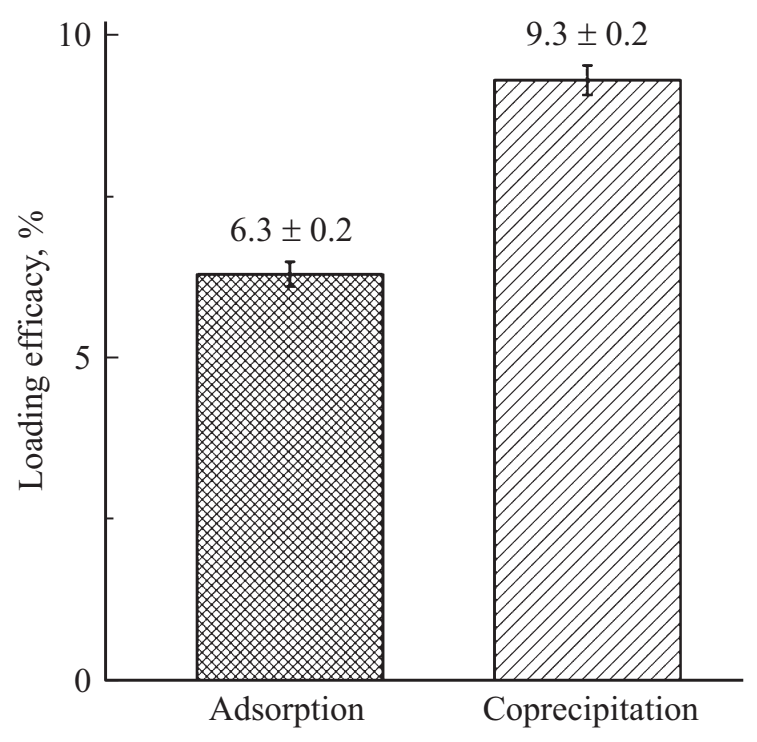

Рис. 4. Сравнение эффективностей загрузки частиц ватерита лекарственным препаратом „Нафтифин“ путем адсорбции и соосаждения. Указаны средние значения \pm стандартное отклонение.

дено методом сканирующей электронной микроскопии. Результат иммобилизации препарата „Нафтифин“ методом адсорбции и соосаждения представлен на рис. $2, b, c$. Как видно из рис. 2 , частицы имеют пористую структуру независимо от метода загрузки. На рис. 2, $a$ пористая структура наиболее отчетливо выражена, так как частицы имеют чистую поверхность. На рис. 2, $b, c$ поверхность частиц визуально выглядит более гладкой, что качественно свидетельствует о присутствии на поверхности и в порах препарата „Нафтифин“. Наиболее гладкую поверхность имеют частицы, полученные методом соосаждения препарата (рис. 2,c).

Для подтверждения факта включения нафтифина в состав частиц ватерита были исследованы спектры комбинационного рассеяния полученных образцов. Эффектив- 

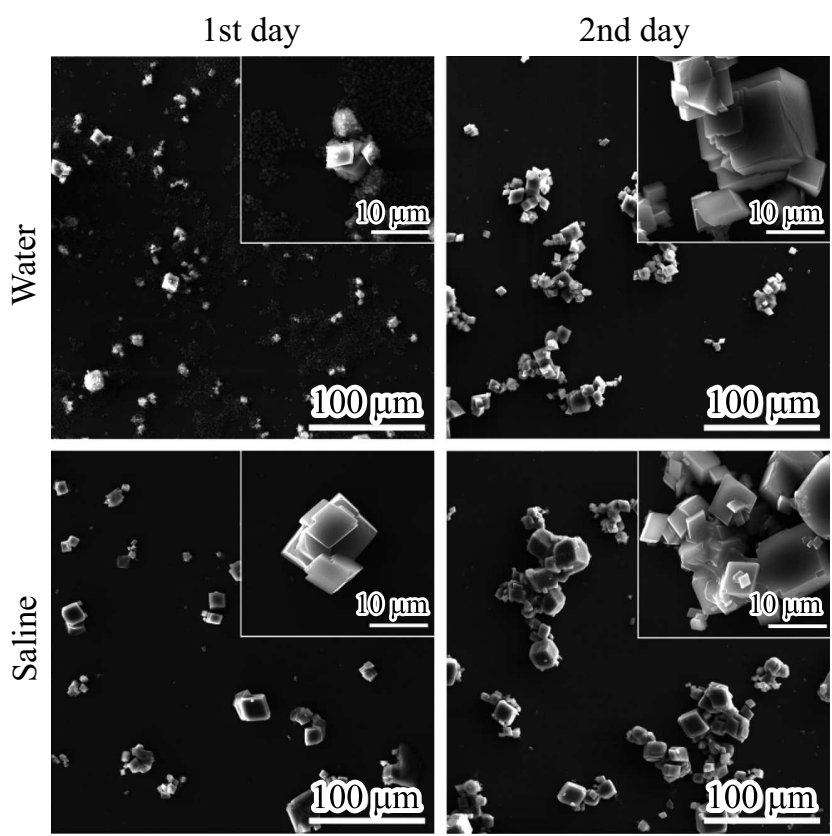

Рис. 5. СЭМ-изображения частиц ватерита, содержащих нафтифин, при инкубировании в воде и физиологическом растворе в течение 2 дней.

ность данного методы была показана во многих работах, где в спектре многокомпонентной системы идентифицировались волновые числа, присущие именно составным частям исследуемой системы [23,24]. На рис. 3 представлены спектры комбинационного рассеяния свободного антимикотика (рис. $3, a$ ) и частиц ватерита, содержащих его (рис. $3, b)$.

Спектр комбинационного рассеяния (КР) нафтифина (рис. 3,a) содержит ряд характерных пиков, в числе которых стоит выделить пик с волновым числом $1655 \mathrm{~cm}^{-1}$. Как известно из литературы [25-29], КР-спектр частиц ватерита обладает характерным пиком на $1090 \mathrm{~cm}^{-1}$. Оба этих пика четко различимы в КРспектре образца, содержащего частицы ватерита с иммобилизованным антимикотиком (рис. $3, b)$. Стоит отметить, что исследуемые контейнеры были предварительно отмыты от не закрепившихся на поверхности молекул нафтифина и высушены. Присутствие таких характерных пиков доказывает успешность иммобилизации терапевтического вещества в объем и на поверхность контейнеров. Низкая интенсивность пика, соответствующего препарату „Нафтифин“, по сравнению с интенсивностью характерного пика ватерита может быть объяснена пропорциями веществ, подвергающихся анализу: процент содержания антимикотика в сухой навеске исследуемых частиц не превышал 10\%, что выразилось в различии интенсивностей в один порядок.

Количественная оценка эффективности загрузки частиц ватерита препаратом „Нафтифин“ была проведена по спектрам его флуоресценции. Под эффективностью загрузки здесь понимается отношение массы иммобилизованного препарата к массе самих частиц ватерита, выраженное в процентах. Вычисления были произведены для обоих методов иммобилизации, результаты представлены на рис. 4. Как видно из рис. 4, максимальное количество иммобилизованного препарата в составе частиц ватерита удалось получить путем его соосаждения в процессе формирования контейнеров, что подтвердило выводы, сделанные при сравнении СЭМ-изображений частиц (рис. 2, $b, c)$. Такой эффект объясняется распределением препарата „Нафтифин“ по всему объему частицы в процессе соосаждения, в то время как при адсорбции препарат размещается лишь в приповерхностной области. Однако оба метода показывают значительно большую эффективность загрузки ватеритной матрицы антимикотиком „Нафтифин“ по сравнению с другими носителями лекарственных средств, например, эмульсиями, где препарат „Нафтифин“ составляет лишь 1\% от композиции [30].

Как было сказано выше, будучи наименее стабильной фазой карбоната кальция, в зависимости от иммерсионной среды ватерит либо полностью растворяется, либо перекристаллизуется в кальцит при контакте с водными растворами. Высвобождение иммобилизованного вещества из ватеритной матрицы-носителя сопровождает этот процесс. Контролируя фазу частиц, можно судить о скорости высвобождения иммобилизованного вещества. В связи с этим было проведено исследование кинетики перекристаллизации частиц ватерита, содержащих антимикотик „Нафтифин“, при инкубации в различных средах (деионизованная вода, физиологический раствор и культуральная среда). Процесс перекристаллизации
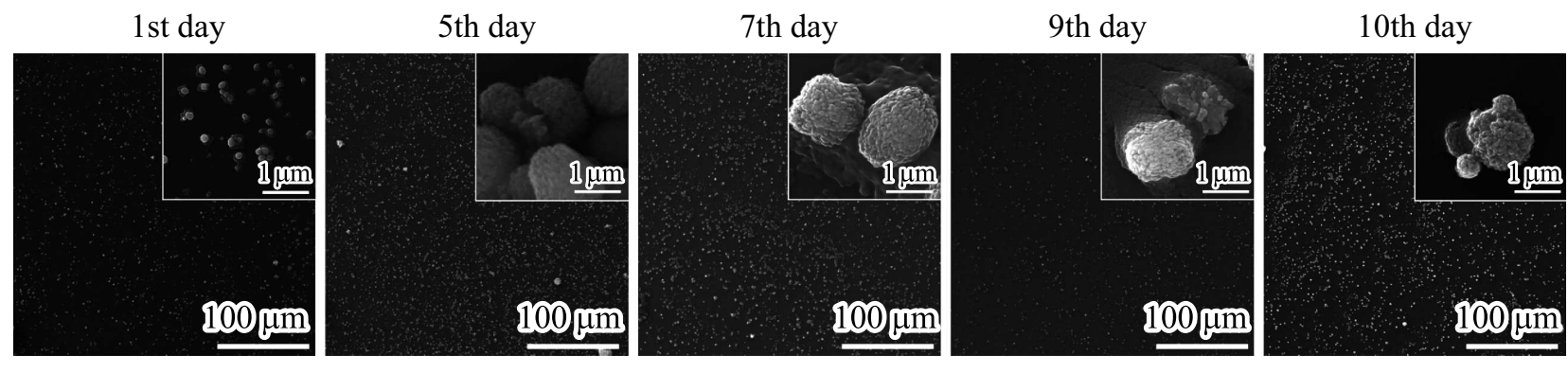

Рис. 6. СЭМ-изображения частиц кальций ватерита, содержащих нафтифин, при инкубировании в культуральной среде в течение 10 дней. 
означает полное высвобождение загруженного вещества, так как происходит полное перестроение кристаллической решетки карбоната кальция [2,31].

Установлено, что при инкубации контейнеров, содержащих нафтифин, в воде через 1 день отмечается присутствие кристаллов кальцита, что свидетельствует о начале процесса перекристаллизации контейнеров, который завершается через 2 дня переходом частиц в фазу кальцита (рис. 5). При инкубации контейнеров в физиологическом растворе процесс перекристаллизации ускорялся, что приводило к появлению большого количества кубических кристаллов кальцита уже в первые сутки инкубации. Такое ускорение процесса обусловлено большей концентрацией ионов, играющих роль дополнительных центров перекристаллизации [31], в растворе по сравнению с деионизованной водой.

В случае инкубирования частиц ватерита в культуральной среде наблюдается значительное замедление скорости перекристаллизации (рис. 6) в результате адсорбции белков, содержащихся в среде, на поверхности частиц, которые образуют, которые образуют так называемую „корону“ [32], что приводит к ее стабилизации и препятствует процессу перекристаллизации. В результате этого частицы не переходили в кальцитную фазу в течение 10 дней наблюдения. Такой эффект стабилизации частиц ватерита в присутствии молекул белка согласуется с ранее полученными данными $[33,34]$. Однако на пятый день отмечались небольшие морфологические изменения частиц. Появляются изъяны на поверхности частиц, их форма претерпевает изменения, переходя от сферической или эллиптической к сложной многогранной форме. Таким образом, наличие дефектов на поверхности частиц ватерита при длительном взаимодействии с культуральной средой свидетельствует о процессе растворения и перекристаллизации и вместе с тем о возможном постепенном высвобождении препарата, включенного в структуру частиц ватерита.

Такое пролонгирование процесса перекристаллизации ватеритных контейнеров и высвобождения лекарственного средства из них можно рассматривать как выгодное преимущество предлагаемой системы для применения in vivo, поскольку при нахождении контейнеров в биологических жидкостях организма будет осуществляться стабилизация их поверхности белками этих жидкостей (,корона“"эффект).

\section{Выводы}

Полученные в ходе исследований результаты свидетельствуют о возможности использования частиц ватерита в качестве контейнеров для иммобилизации антигрибкового препарата „Нафтифин“ с высокой степенью его загрузки и длительным высвобождением в среде, содержащей белковые компоненты. Совместное применение методов флуориметрии, спектроскопии комбинационного рассеяния света, а также сканирующей электрон- ной микроскопии обеспечило комплексное исследование процесса иммобилизации лекарственного препарата. Хорошая корреляция полученных результатов говорит об их эффективности и достоверности.

\section{Финансирование работы}

Исследование выполнено за счет средств гранта Российского научного фонда (проект № 17-73-20172).

\section{Список литературы}

[1] Soliman G.M. // Int. J. Pharm. 2017. V. 523. N 1. P. 15-32.

[2] Ogino T., Suzuki T., Sawada K. // Geochim. Cosmochim. Acta. 1987. V. 51. N 10. C. 2757-2767.

[3] Svenskaya Y.I., Pavlov A.M., Gorin D.A., Gould D.J., Parakhonskiy B.V., Sukhorukov G.B. // Colloids and Surfaces B. 2016. V. 146. P. 171-179.

[4] Parakhonskiy B., Zyuzin M.V, Yashchenok A., Romero S.C., Rejman J., Möhwald H., Parak W.J., Skirtach A.G. // J. Nanobiotechnology. 2015. P. 1-13.

[5] Biradar S., Ravichandran P., Gopikrishnan R., Goornavar V., Hall J.C., Ramesh V., Baluchamy S., Jeffers R.B., Ramesh G.T. // Journal of Nanoscience and Nanotechnology. 2011. V. 11. N 8. P. 6868-6874.

[6] Svenskaya Y., Parakhonskiy B., Haase A., Atkin V., Lukyanets E., Gorin D., Antolini R. // Biophys. Chem. 2013. V. 182. P. $11-15$.

[7] Ma M., Zhu J. // Recent patents on nanotechnology. 2010. V. 4. N 3. P. 164-170.

[8] Trushina D.B., Bukreeva T.V., Kovalchuk M.V., Antipina M.N. // Mater. Sci. Engineer. C. 2014. V. 45. P. 644-658.

[9] Volodkin D. // 2014. V. 207. P. 306-324.

[10] Sukhorukov G.B., Volodkin D.V, Gu A.M. // J. Mater. Chem. 2004. V. 14. P. 2073-2081.

[11] Sergeeva A., Sergeev R., Lengert E., Zakharevich A., Parakhonskiy B.V., Gorin D., Sergeev S., Volodkin D. // ACS Appl. Mater. \& Interfaces. 2015. V. 7. N 38. P. 21315-21325.

[12] Volodkin D.V, Larionova N.I., Sukhorukov G.B. // Biomacromolecules. 2004. V. 5. N 5. P. 1962-1972.

[13] Gusliakova O., Atochina-Vasserman E.N., Sindeeva O., Sindeev S., Pinyaev S., Pyataev N., Revin V., Sukhorukov G.B., Gorin D., Gow A.J. // Frontiers in Pharmacology. 2018. V. 9. P. 1-13.

[14] Joshi A.B., Srivastava R. // Adv. Sci. Lett. 2009. V. 2. N 3. P. $329-336$

[15] Li J., Jiang Z., Wu H., Long L., Jiang Y., Zhang L. // Composites Sci. Techno. 2009. V. 69. N 34. P. 539-544.

[16] Dizaj S.M., Barzegar-jalali M., Zarrintan M.H., Adibkia K., Lotfipour F., Barzegar-jalali M., Zarrintan M.H., Adibkia K., Lotfipour F. // Expert Opinion on Drug Delivery. 2015. V. 12. N 10. P. 1649-1660.

[17] Qiu N., Yin H., Ji B., Klauke N., Glidle A., Zhang Y., Song H., Cai L., Ma L., Wang G., Chen L., Wang W. // Mater. Sci. Engineer. C. 2012. V. 32. N 8. P. 2634-2640.

[18] Parakhonskiy B., Tessarolo F., Haase A., Antolini R. // Adv. Sci. Technol. 2013. V. 86. P. 81-85.

[19] Parakhonskiy B.V, Foss C., Carletti E., Fedel M., Haase A., Motta A., Migliaresi C., Antolini R. // /Biomater Sci. 2013. V. 1. N 12. P. 1273-1281. 
[20] Parakhonskiy B.V., Haase A., Antolini R. // Ang. Chemie Int. Ed. 2012. V. 51. N 5. P. 1195-1197.

[21] Stutz A., Granitzer W., Berneyt D. // J. Med. Chem. 1986. N 17. P. $112-125$.

[22] Georgopoulos A., Petranyi G., Mieth H., Drews J., Georgopoulos M.A., Abstr P., Conf I. // Antimicrobial agents and chemotherapy. 1981. V. 19. N 3. P. 386-389.

[23] Воробьев В.В. и др. // Опт. и спектр. 2018. Т. 124. В. 5. C. 617-622.

[24] Смирнова Т.П. и др. // Опт. и спектр. 2011. Т. 110. № 1. C. 60-64.

[25] Kontoyannis C.G., Vagenas N.V. // Analyst. 2000. V. 125. N 2. P. 251-255.

[26] Gabrielli C., Jaouhari R., Joiret S., Maurin G. // J. Raman Spectrosc. 2000. V. 31. N 6. P. 497-501.

[27] Behrens G., Kuhn L.T., Ubic R., Heuer A.H. // Spectrosc. Lett. 1995. V. 28. N 6. P. 983-995.

[28] Wehrmeister U., Soldati A.L., Jacob D.E., Häger T., Hofmeister W. // J. Raman Spectrosc. 2010. V. 41. N 2. P. 193-201.

[29] Parakhonskiy B.V., Svenskaya Y.I., Yashchenok A., Fattah H.A., Inozemtseva O.A., Tessarolo F., Antolini R., Gorin D.A. // Colloids and Surfaces B. 2014. V. 118. P. 243-248.

[30] Erdal M.S. et al. // Int. J. Nanomed. 2016. V. 11. P. 1027.

[31] Ogino T., Suzuki T., Sawada K. // J. Crystal Growth. 1990. V. 100. N 1-2. P. 159-167.

[32] Lynch I., Dawson K.A. // Nano Today. 2008. V. 3. N 1-2. P. 40-47.

[33] Svenskaya Y.I. et al. // Colloids and Surfaces B. 2016. V. 146. P. 171-179.

[34] Трушина Д.Б., Бородина Т.Н., Артемов В.В., Букреева Т.В. // ЖТФ. 2018. Т. 88. В. 9. С. 1387-1393. 